\title{
ANAEROBIC RELEASE OF PHOSPHATE FROM ACTIVATED SLUDGE: ITS RESPONSE TO PHYSICAL AND CHEMICAL STRESSES
}

\author{
KIYOSHI TODA*, QIN YE AND HISAO OHTAKE \\ Institute of Applied Microbiology, University of Tokyo, \\ Bunkyo-ku, Tokyo 113, Japan
}

(Received August 24, 1989)

\begin{abstract}
Activated sludge which had been subjected to an anaerobic-aerobic cycle showed high rates of anaerobic release of phosphate, followed by excess phosphate uptake under aerobic conditions. Addition of carbon and energy sources was essential to anaerobic release of phosphate, and no significant release of phosphate occurred in the absence of added substrates. Heating activated sludge $\left(90^{\circ} \mathrm{C}\right.$ for $\left.2 \mathrm{~min}\right)$ strongly inhibited anaerobic release of phosphate. Treatment of activated sludge with chemical reagents including sodium hypochlorite, benzalkonium chloride and ethanol greatly inhibited phosphate release. Increasing the osmotic pressure in the medium adding sodium chloride and sucrose also inhibited the release. These results showed that the anaerobic release of phosphate from activated sludge which had been acclimated to an anaerobic-aerobic cycle is principally attributable to a biological mechanism.
\end{abstract}

The enhanced removal of phosphate in the activated sludge process has been well documented $(2,7,9)$, but attempts to elucidate the exact mechanism have not yet been successful. For biological phosphorus removal, it is necessary to subject cyclically activated sludge to aerobic and anaerobic conditions(3). Under the anaerobic conditions, activated sludge releases phosphate, and excess uptake of phosphate occurs during the subsequent aerobic conditions. The uptake and release of phosphate are reversible, and the relation between release and subsequent uptake of phosphate seems to be the key to the mechanism of the excess phosphorus removal (10).

There is general agreement that excess phosphorus removal is due to the intracellular accumulation of polyphosphates by sludge microorganisms. Polyphosphate-accumulating bacteria have been isolated from activated sludge, and from

* Address reprint requests to: Dr. K. Toda, Institute of Applied Microbiology, University of Tokyo, Bunkyo-ku, Tokyo 113, Japan. 
pure culture studies many workers have proposed that excess phosphorus removal in the activated sludge process is principally via a biological mechanism $(4,6)$. However, the role and mechanism of anaerobic phosphate release from activated sludge is still controversial, and nobody has as yet answered conclusively whether the release of phosphate is a purely biological phenomenon.

This paper presents the results of a study of anaerobic release of phosphate from activated sludge under the effects of various factors which are generally inhibitory for the biological activities of sludge microorganisms.

\section{MATERIALS AND METHODS}

Sludge sample. Activated sludge was taken from a bench-scale activated sludge unit having anaerobic and aerobic zones of complete liquid mixing and a sedimentation zone for free settling of activated sludge. The activated sludge was acclimated in a synthetic wastewater containing (grams per liter of tap water): sodium acetate, 1.36; polypepton, 0.2 ; yeast extract, $0.02 ; \mathrm{NaHCO}_{3}, 0.15$; $\mathrm{MgSO}_{4} \cdot 7 \mathrm{H}_{2} \mathrm{O}, 0.15 ; \mathrm{NaCl}, 0.1 ; \mathrm{CaCl}_{2} \cdot 2 \mathrm{H}_{2} \mathrm{O}, 0.05 ; \mathrm{KH}_{2} \mathrm{PO}_{4}, 0.45$. The hydraulic detention time of the wastewater in the anaerobic and aerobic zones were $2.3 \mathrm{~h}$ and $3.3 \mathrm{~h}$, respectively. The flow rate of the return sludge from the sedimentation zone to the anaerobic zone was 0.33 times that of the influent flow. The suspended solid concentration of the mixed liquor in the aerobic zone was $3.2-5.3 \mathrm{~g} / l$. The activated sludge process was operated for two and half months at room temperature, the variation of which was in the range of $20-33^{\circ} \mathrm{C}$. The inorganic phosphate concentration in the aerobic zone was in the order of $0.1 \mathrm{mg}-\mathrm{P} / l$, those in the influent and the anaerobic zone were around $5 \mathrm{mg}-\mathrm{P} / l$ and $10.2-36.3 \mathrm{mg}-\mathrm{P} / \mathrm{l}$, respectively.

Batch experiments. A series of batch experiments was undertaken to study the effects of physical and chemical stresses on release of phosphate by activated sludge. Mixed liquor $(50 \mathrm{ml})$ from the bench-scale activated sludge unit was centrifuged at $6,000 \mathrm{rpm}$ for $10 \mathrm{~min}$, and resuspended in $50 \mathrm{ml}$ of the synthetic wastewater in a $300-\mathrm{ml} \mathrm{flask} \mathrm{immersed} \mathrm{in} \mathrm{a} 30^{\circ} \mathrm{C}$ water bath. The mixed liquor was incubated anaerobically for $2.5 \mathrm{~h}$ then aerated for a further $3.5 \mathrm{~h}$ through a sintered glass sparger at the rate of $3.6 \mathrm{vvm}$. The aeration was conducted to examine the phosphate-uptake ability of activated sludge under aerobic conditions. One $\mathrm{ml}$ samples were taken hourly from the flask and centrifuged at $12,000 \mathrm{rpm}$ for $5 \mathrm{~min}$. The supernatant was diluted for phosphate measurement. Orthophosphate was determined by the ascorbic acid method (1).

\section{RESULTS}

Activated sludge which had been subjected to an anaerobic-aerobic cycle showed anaerobic release of phosphate, followed by phosphate uptake under aerobic conditions (Fig. 1). Adding carbon and energy sources was essential for anaerobic release of phosphate. No significant release of phosphate occurred in the absence 


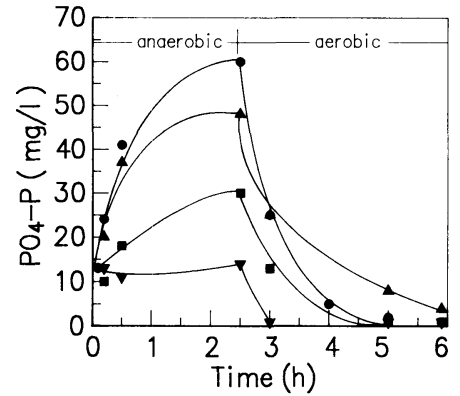

Fig. 1 .

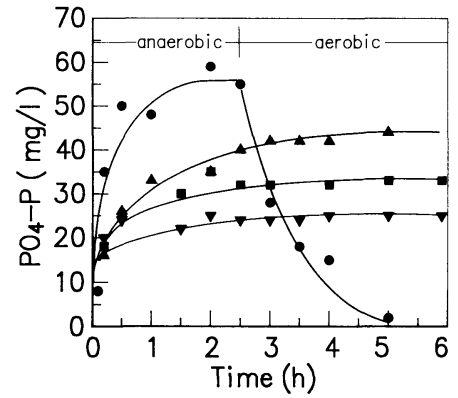

Fig. 2.

Fig. 1. Effects of adding carbon and energy sources on release and uptake of phosphate by activated sludge. Symbols: $\boldsymbol{\nabla}$, no addition (control); $\boldsymbol{\Delta}$, + acetate $(1.36 \mathrm{~g} / l)$; $\mathbf{\square}$, + peptone $(0.2 \mathrm{~g} / l)$ and yeast extract $(0.02 \mathrm{~g} / l) ; \bullet$, + acetate $(1.36 \mathrm{~g} / l)$, peptone $(0.2 \mathrm{~g} / l)$ and yeast extract $(0.02 \mathrm{~g} / l)$.

Fig. 2. Effects of heating stress on release and uptake of phosphate by activated sludge. Symbols: $\bullet$, control $\left(30^{\circ} \mathrm{C}\right) ; \Delta$, heated at $48^{\circ} \mathrm{C}$ for $2 \mathrm{~min}$; $\mathbf{\square}$, heated at $60^{\circ} \mathrm{C}$ for $2 \mathrm{~min} ; \boldsymbol{\nabla}$, heated at $90^{\circ} \mathrm{C}$ for $2 \mathrm{~min}$.

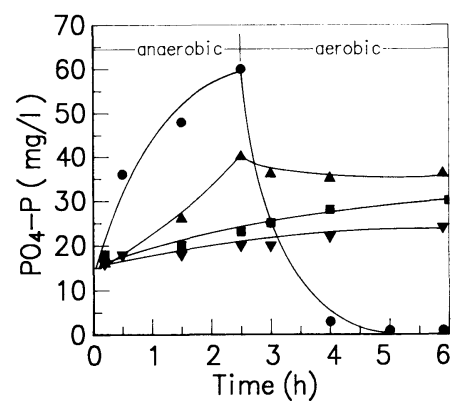

Fig. 3. Effects of osmotic pressure on release and uptake of phosphate by activated sludge. Symbols: $\bullet$, no addition (control); $\boldsymbol{\Lambda}, 1.5 \% \mathrm{NaCl} ; \mathbf{\square}, 3.0 \% \mathrm{NaCl} ; \boldsymbol{\nabla}, 5.0 \% \mathrm{NaCl}$.

of added energy and carbon sources. Rates of phosphate release were greatly increased by adding sodium acetate.

Heating activated sludge inhibited release of phosphate (Fig. 2). In this experiment activated sludge was heated for $2 \mathrm{~min}$ at 48,60 and $90^{\circ} \mathrm{C}$, resuspended in the synthetic wastewater then incubated at $30^{\circ} \mathrm{C}$. The degree of inhibition increased with increasing heating temperature. Heating at $90^{\circ} \mathrm{C}$ strongly inhibited release of phosphate, but a considerable amount of phosphate was released at $48^{\circ} \mathrm{C}$.

Anaerobic release of phosphate was also strongly inhibited by increasing osmotic pressure by adding sodium chloride to the synthetic wastewater (Fig. 3). Though some phosphate release occurred at $1.5 \% \mathrm{NaCl}$, there was no significant release when the concentration of $\mathrm{NaCl}$ exceeded $5 \%$. Similar inhibition also 
Table 1. Effects of various physical and chemical stresses on the ability of activated sludge to release and take up phosphate.

\begin{tabular}{|c|c|c|}
\hline \multirow{2}{*}{ Physical and chemical stress } & \multicolumn{2}{|c|}{ Relative activity ( $\%$ of control) } \\
\hline & Phosphate release $^{a}$ & Phosphate uptake ${ }^{b}$ \\
\hline Control & 100 & 100 \\
\hline \multicolumn{3}{|l|}{ Heating } \\
\hline $48^{\circ} \mathrm{C} ; 2 \mathrm{~min}$ & 61 & 0 \\
\hline $60^{\circ} \mathrm{C} ; 2 \mathrm{~min}$ & 39 & 0 \\
\hline $90^{\circ} \mathrm{C} ; 2 \mathrm{~min}$ & 16 & 0 \\
\hline \multicolumn{3}{|l|}{ Osmotic pressure } \\
\hline $1.5 \% \mathrm{NaCl}$ & 52 & 12 \\
\hline $3.0 \% \mathrm{NaCl}$ & 14 & 0 \\
\hline $5.0 \% \mathrm{NaCl}$ & 2 & 0 \\
\hline $5.0 \% \mathrm{KCl}$ & 9 & 0 \\
\hline $5.0 \%$ Sucrose & 9 & 0 \\
\hline $10.0 \%$ Sucrose & 0 & 0 \\
\hline $20.0 \%$ Sucrose & 0 & 0 \\
\hline \multicolumn{3}{|l|}{ Nutrient depletion } \\
\hline -acetate & 36 & $50^{*}$ \\
\hline —peptone; —yeast extract & 74 & $75^{*}$ \\
\hline no carbon and energy sources & 2 & $22 *$ \\
\hline \multicolumn{3}{|l|}{ Treatment with chemical reagents } \\
\hline $0.1 \%$ sodium hypochlorite; $2 \mathrm{~h}$ & 20 & 0 \\
\hline $70 \%$ ethanol; $2 \mathrm{~h}^{\dagger}$ & 36 & 0 \\
\hline $0.1 \%$ benzalkonium chloride & 12 & 0 \\
\hline \multicolumn{3}{|l|}{ Antibiotics } \\
\hline $100 \mathrm{mg} / \mathrm{l}$ Nystatin & 100 & 100 \\
\hline $100 \mathrm{mg} / \mathrm{l}$ Cycloheximide & 100 & 100 \\
\hline $50 \mathrm{mg} / \mathrm{l}$ Tetracycline & 100 & 100 \\
\hline
\end{tabular}

a The amount of phosphate released during the 2.5-h anaerobic period, relative to that of the control.

b The amount of phosphate uptake by activated sludge during the 3.5 -h aerobic period, relative to that of the control.

* Phosphate released anaerobically was completely removed (see Fig. 1).

+ A rapid leakage of phosphate was observed within a few minutes just after the start of incubation.

occurred when the osmotic pressure was increased with nonelectrolytes (Table 1). Adding sucrose at concentrations of 5-20\%, greatly inhibited phosphate release.

Treatment of activated sludge with chemical reagents including sodium hypochlorite, benzalkonium chloride and ethanol strongly inhibited phosphate release from activated sludge (Table 1). In this experiment activated sludge was treated with chemical reagents for $2 \mathrm{~h}$ at $30^{\circ} \mathrm{C}$, then washed with the synthetic wastewater. The activated sludge was used for the release and uptake experiments. Effects of sodium hypochlorite and ethanol were tested because they are typical bactericides. Benzalkonium chloride was used to study the effects of surfactants. Table 1 also summarizes the effects of physical and chemical stresses on the ability 
of activated sludge to release and take up phosphate.

\section{DISCUSSION}

In this study we examined the effects of physical and chemical stresses on anaerobic phosphate release from activated sludge. Clearly the release was sensitive to heating, osmotic pressure and treatment with chemicals including sodium hypochlorite, benzalkonium chloride and ethanol. These stresses generally inhibit microbial activities. For example, osmotic stress can decrease the turgor pressure of living organisms, and that decrease deforms the cell membrane, which leads to inactivation of membrane-embedded proteins. The results of the present study indicate that phosphate release from activated sludge is principally a physiological phenomenon which is induced by anaerobic stress.

There was a clear difference in response to heat stress between the release and uptake of phosphate by activated sludge (Fig. 2). The uptake was completely inhibited by heating at $48^{\circ} \mathrm{C}$, whereas the release occurred at temperatures of 48 and $60^{\circ} \mathrm{C}$. Clearly the release is more resistant than the uptake to heat stress. We have reported (11) that mixed cultures of two bacterial strains (an obligate aerobe and a facultative anaerobe) showed anaerobic phosphate release, and excess uptake of phosphate under the subsequent aerobic conditions. Since activated sludge consists of heterogeneous populations of bacteria, it is conceivable that different groups of bacteria were responsible for the phosphate release and excess phosphate uptake. If that is so, the microbes responsible for anaerobic phosphate release would be moderately thermostable. However, to determine this, it is necessary to isolate the different groups of bacteria that produce the characteristic pattern of release and uptake of phosphate in an anaerobic and aerobic cycle as shown in Figs. 1-3.

We observed that anaerobic release of phosphate required added carbon and energy sources. It appears that adding sodium acetate affected phosphate release more than peptone and yeast extracts did. Increasing phosphate release by adding acetate has also been reported (5,8). Marais et al. (5) hypothesized that degradation of polyphosphates in activated sludge provides the energy to take up acetate from solution under anaerobic conditions, and phosphate resulting from the hydrolysis of polyphosphates diffuses out through the cytoplasmic membrane. However, a definite relation between acetate uptake and phosphate release has not yet been determined. Biochemical and physiological studies will lead eventually to further understanding of anaerobic phosphate release by activated sludge.

This work was supported by a grant from the Ministry of Education, Science and Culture of Japan.

\section{REFERENCES}

1) American Public Health Association, Standard Methods for the Examination of Water and Wastewater, 14th ed., American Public Health Association, Inc., New York (1976), p. 481. 
2) Barnard, J. L., A review of biological phosphorus removal in the activated sludge process. Water $S A, 2,136-144$ (1976).

3) Davellar, D., Davies, T. R., and Wiechers, S. G., The significance of an anaerobic zone for the biological removal of phosphate from wastewaters. Water $S A, 4,54-60$ (1978).

4) Deinema, M. H., Habets, L. H. A., Scholten, J., Turkstra, E., and Webers, H. A. A. M., The Accumulation of polyphosphate in Acinetobacter spp. FEMS Microbiol. Lett., 9, 275-279(1980).

5) Florentz, M., Granger, P., and Hartemann, P., Use of ${ }^{31} \mathrm{P}$ nuclear magnetic resonance spectroscopy and electron microscopy to study phosphorus metabolism of microorganisms from wastewaters. Appl. Environ. Microbiol., 47, 519-525 (1984).

6) Florentz, M. and Hartemann, P., Screening for phosphate accumulating bacteria isolated from activated sludge. Environ. Technol. Lett., 5, 457-463 (1984).

7) Levin, G. V. and Shapiro, J., Metabolic uptake of phosphorus by wastewater organisms. Water Pollut. Control. Fed., 37, 800-821 (1965).

8) Marais, G. V. R., Loewenthal, R. E., and Siebritz, I., Review: Observations supporting phosphate removal by biological excess uptake. Water Sci. Technol., 15, 15-41 (1983).

9) McLaren, A. R. and Wood, R. J., Effective phosphorus removal from sewage by biological means. Water SA, 2, 47-50 (1976).

10) Ohtake, H., Takahashi, K., Tsuzuki, Y., and Toda, K., Uptake and release of phosphate by a pure culture of Acinetobacter calcoaceticus. Water Res., 19, 1587-1594 (1985).

11) Ye, Q., Ohtake, H., and Toda, K., Phosphorus removal by pure and mixed cultures of microorganisms. J. Ferment. Technol., 66, 207-212 (1988). 